\title{
25 Research Suare \\ Arabidopsis V-ATPase d2 subunit plays a role in plant responses to oxidative stress
}

\section{Shuang Feng}

Northeast Forestry University

\section{Yun Peng}

Northeast Agricultural University

Enhui Liu

Northeast Agricultural University

Hongping Ma

Northeast Agricultural University

Kun Qiao

Northeast Agricultural University

Aimin Zhou

Northeast Agricultural University

Shenkui Liu ( $\nabla$ shenkuiliu@nefu.edu.cn )

Zhejiang $A$ and $F$ University

\section{Yuanyuan Bu}

Northeast Forestry University https://orcid.org/0000-0001-6469-6279

\section{Research article}

Keywords: V-ATPase d subunit, Oxidative stress, $\mathrm{H}+$ flux, plasma membrane H+-ATPase, Arabidopsis

Posted Date: March 23rd, 2020

DOI: https://doi.org/10.21203/rs.3.rs-17572/v1

License: (c) (1) This work is licensed under a Creative Commons Attribution 4.0 International License. Read Full License 


\section{Abstract}

Background: Vacuolar-type H + -ATPase (V-ATPase) is a multisubunit proton pump located on the endomembranes, which plays an important role in plant growth. The Arabidopsis V-ATPase $d$ subunit consists of two isoforms, AtVHA-d1 and AtVHA-d2.

Results: In this study, the function of the AtVHA-d2 gene was investigated. Histochemical analysis revealed that the AtVHA-d1 and AtVHA-d2 genes were generally and highly overlapping expressed in multiple tissues at different developmental stages of Arabidopsis. Subcellular localization showed that AtVHA-d2 was mainly localized to the vacuole. The AtVHA-d2 expression was significantly induced by oxidative stress. Furthermore, the phenotypic analysis showed that the atvha-d 2 mutant was sensitive to oxidative stress. The non-invasive micro-test measurement demonstrated that the net $\mathrm{H}+$ influx in the atvha-d2 roots was weaker than that of the wild type under normal conditions. However, oxidative stress resulted in the $\mathrm{H}+$ efflux in atvha-d2 roots, which was significantly different from the wild type. RNA-seq combined with qPCR analysis showed that the expression of several members of the plasma membrane $\mathrm{H}+$-ATPase gene ( AtAHA ) family in atvha-d2 were significant different from wild type under normal and oxidative stress.

Conclusion: Overall, our results indicate that AtVHA-d2 plays a role in Arabidopsis in response to oxidative stress by affecting $\mathrm{H}+$ flux and AtAHA gene expression.

\section{Background}

The $\mathrm{pH}$ homeostasis in the endomembrane system is important for secondary active transport, cargo sorting, and protein trafficking [1-4]. Plants employ three classes of proton pumps to regulate cellular $\mathrm{pH}$ homeostasis: (i) plasma membrane $\mathrm{H}^{+}$-ATPase (P-ATPase); (ii) vacuolar $\mathrm{H}^{+}$-pyrophosphatase (V-PPase); and (iii) vacuolar-type $\mathrm{H}^{+}$-ATPase (V-ATPase) [1]. V-ATPase uses the energy released by ATP hydrolysis to transport proton $\left(\mathrm{H}^{+}\right)$across the membrane to regulate $\mathrm{pH}$ in the plant endomembrane system. V-ATPase is a highly conserved, multisubunit complex that consists of two domains, the integral membrane $V_{0}$ domain and the cytosolic $\mathrm{V}_{1}$ domain. The $\mathrm{V}_{0}$ domain, which consists of six subunits (VHA-a, VHA-c, VHA$\left.c^{\prime \prime}, \mathrm{VHA}-\mathrm{d}, \mathrm{VHA}-\mathrm{e}\right)$, is responsible for $\mathrm{H}^{+}$translocation across membranes. The $\mathrm{V}_{1}$ domain, which consists of eight subunits (subunits $A$ to $H$ ), is responsible for ATP hydrolysis $[5,6]$. The $V_{1}$ domain is assembled into a complete enzyme by binding to the $\mathrm{V}_{0}$ domain; this binding is reversible [5].

Currently, it is considered that Arabidopsis V-ATPase is mainly located on trans-Golgi network/early endosome (TGN/EE) and in vacuoles that are marked by the differential localization of three isoforms of AtVHA-a (AtVHA-a1, AtVHA-a2, and AtVHA-a3) [7, 8]. The studies of atvha-a1 single- and atvha-a2/a3 double-mutant showed that V-ATPase in the TGN/EE is required for exocytosis and recycling, while VATPase in the vacuole is required for effective nutrient storage [7-9]. In addition, V-ATPase plays a role in response to various stresses. For example, the growth of deetiolated3 (det3), a mutant of AtVHA-C, was significantly inhibited and was salt-sensitive $[10,11]$. The atvha-a1 and atvha-c5 mutants are also 
sensitive to salt $[8,12]$. Yeast two-hybrid analysis has shown that AtVHA-B interacted directly with salt overly sensitive 2 (AtSOS2) [10]. These studies suggest that V-ATPase may be involved in the plant salt stress response. Other studies have shown that V-ATPase in yeast plays a role in the oxidative stress response $[13,14]$. Our previous studies have shown that expression of AtVHA-c genes is not only induced by salt stress, but also induced by oxidative stress in varying degrees [15]. However, it is not clear whether the plant V-ATPase is involved in the oxidative stress response.

In the whole enzyme of V-ATPase, VHA-d is located on top of the ring formed by the six VHA-c subunits. It thus participates in control of either the reversible dissociation of $V_{0}$ and $V_{1}$ domains or coupling of proton transfer and ATP hydrolysis [5]. The Arabidopsis AtVHA-d contains two isoforms, AtVHA-d1 and AtVHA-d2 [16]. At present, the expression pattern, subcellular localization and function of the AtVHA-d genes are not clear. In this study, we investigated the expression patterns of AtVHA-d genes by promoterdriven $\beta$-glucuronidase (GUS) expression. The subcellular localization of AtVHA-d2 was observed by green fluorescent protein (GFP) marker, the expression of AtVHA-d genes under various stresses was analyzed by quantitative real-time PCR (qPCR), and the phenotype and root $\mathrm{H}^{+}$flux of the atvha-d2 mutant under various stresses were investigated. Differentially expressed genes (DEGs) between the atvha-d2 mutant and wild-type were identified and validated by RNA sequencing (RNA-seq) and qPCR.

\section{Results}

\section{Tissue specificity of AtVHA-d genes expression}

AtVHA-d1 and AtVHA-d2 are two highly similar genes, and they share $99.4 \%$ identity in amino acid sequence (Fig. 1A). TMHMM prediction showed that both AtVHA-d1 and AtVHA-d2 proteins had no transmembrane domain (Fig. 1B). To verify whether functions of AtVHA-d1 and AtVHA-d2 are redundant, their expression patterns were investigated by promoter-driven GUS reporter transgene. During early seedling development, expression of proAtVHA-d1:GUS and proAtVHA-d2:GUS was detected in all tissues of the seedlings, including roots, stems, leaves, and stipule primordia (Fig. 2A and B). In mature plants, both proAtVHA-d1:GUS and proAtVHA-d2:GUS were expressed in flowers and siliques, including sepal, anther, and embryo sac (Fig. 2C and D). In conclusion, AtVHA-d1 and AtVHA-d2 genes are broadly expressed in plant tissues and exhibit overlapping expression patterns.

\section{Subcellular localization of AtVHA-d2}

Only two amino acids of AtVHA-d1 and AtVHA-d2 were different, so the subcellular localization of one member (AtVHA-d2) in Arabidopsis was investigated using GFP as a fusion protein marker. The confocal images showed that the GFP signals were mainly localized to the vacuoles in root cells of Arabidopsis seedlings stably expressing AtVHA-d2-GFP (Fig. 3).

\section{Sensitivity of the atvha-d2 mutant to multiple stresses}


qPCR analysis showed that the expression of AtVHA-d1 was not obviously affected by salt, osmotic, oxidative, and ABA stress, but AtVHA-d2 was significantly induced. Under cold and heat treatment, the expression of both AtVHA-d1 and AtVHA-d2 was not obviously affected (Fig. 4A and B). The result suggest that AtVHA-d2 may play a role in Arabidopsis response to multiple stresses. To better understand the role of AtVHA-d2 in response to multiple stresses, the T-DNA insertion mutant of AtVHA-d2 was identified. The genomic PCR and sequencing analysis showed that T-DNA was inserted into the fifth exon of the AtVHA-d2 gene (Fig. 5A-C; Additional file 1: Fig. S1). qPCR analysis revealed that the AtVHA-d2 mRNA level in atvha-d2 was approximately $10 \%$ of that in Col-0. However, the AtVHA-d1 mRNA level in atvha-d2 was similar to that of Col-0 (Fig. 5D).

The phenotypes of the atvha-d2 mutant and Col-0 were compared under normal and multiple stress conditions. On 1/2 MS medium or $1 / 2 \mathrm{MS}$ medium supplemented with $\mathrm{NaCl}(75$ and $100 \mathrm{mM}), \mathrm{H}_{2} \mathrm{O}_{2}(1$ and $2 \mathrm{mM}$ ), and mannitol (175 and $200 \mathrm{mM}$ ), the primary root length of the atvha-d2 mutant was generally lower than that of Col-0 (Fig. $6 \mathrm{~A}$ and B). Under $\mathrm{H}_{2} \mathrm{O}_{2}$ and mannitol stress, the fresh weight of the atvha-d2 seedlings was significantly lower than that of Col-0, and there were no significant differences in the normal conditions (1/2 MS medium) (Fig. 6C). The relative root length analysis showed that the inhibition ratio of $\mathrm{H}_{2} \mathrm{O}_{2}$ on the primary root growth of the atvha-d2 mutant was significantly higher than that of Col-0 (Fig. 6D). These results suggest that the atvha-d2 mutant is sensitive to oxidative stress.

\section{$\mathrm{H}^{+}$flux in root of the atvha-d2 mutant under multiple stresses}

\section{The net $\mathrm{H}^{+}$flux in the roots of the atvha-d2 and Col-0} seedlings were monitored using the NMT. The $\mathrm{H}^{+}$influx in the roots of atvha-d2 and Col-0 seedlings grown on 1/2 MS medium was observed, but the rate of $\mathrm{H}^{+}$influx in atvha-d2 was significantly lower than that in Col-0 (Fig. 7A and B). The result indicated that $\mathrm{H}^{+}$flux in the atvha-d2 roots is impaired. Further, the $\mathrm{H}^{+}$flux in the roots of atvha-d2 and Col-0 was compared under multiple stresses. Similar to that in untreated roots (1/2 MS medium), the mannitol treatment had no obvious effect on $\mathrm{H}^{+}$flux in the atvha-d2 and $\mathrm{Col}-0$ roots. The $\mathrm{NaCl}$ treatment resulted in the $\mathrm{H}^{+}$efflux in both atvha-d2 and Col-0 roots, but there was no 


\section{significant difference between them. Under the $\mathrm{H}_{2} \mathrm{O}_{2}$}

\section{treatment, an $\mathrm{H}^{+}$influx in the Col-0 roots was observed; however, in the atvha-d2 roots, an $\mathrm{H}^{+}$efflux was observed (Fig. 7A and $B$ ). The result indicates that $\mathrm{H}_{2} \mathrm{O}_{2}$ treatment significantly affects the $\mathrm{H}^{+}$flux in the atvha-d2 roots.}

\section{Identification of DEGs between atvha-d2 and wild-type under normal and oxidative stress}

To identify DEGs between atvha-d2 mutant and Col-0, RNA-seq was performed. Under normal and oxidative conditions, a total 278 DEGs (Additional file 2: Table S1) were identified in atvha-d2 mutant relative to the Col-0 (Fig. 8A and B). These DEGs were most significantly enriched into the V-type ATPase, eukaryotes module from the KEGG database (Fig. 8C). This module contains 28 genes (Additional file 3 : Table S2); with the exception of AtVHA-d2, the expression of the remaining 27 genes was up-regulated in the atvha-d2 mutant (Fig. 8D). The result showed that the inhibition of the AtVHA-d2 expression results in an up-regulation of the expression of other V-ATPase assembly subunits under normal and oxidative stress. Moreover, the expression of genes encoding P-ATPase (AtAHA) and V-PPase (AtAVP) in Col-0 and atvha-d2 showed difference under normal and oxidative stress (Fig. 8E, F).

\section{Expression of AtAHA and AtAVP genes in atvha-d2 and wild-type under normal and oxidative stress}

The expression of 11 AtAHA and 2 AtAVP genes in the atvha-d2 mutant and Col-0 under normal and oxidative stress was compared by qPCR. Among the 11 AtAHA genes, the expression of AtAHA1, AtAHA2, and AtAHA7 in the atvha-d2 mutant was significantly lower than that of Col-0, while that of AtAHA4, AtAHA5, and AtAHA8 was significantly higher than that of Col-0 under normal conditions. After $24 \mathrm{~h}$ of oxidative stress, expression of AtAHA1, AtAHA2, AtAHA4, and AtAHA5 in the atvha-d2 mutant was significantly higher than those of Col-0 (Fig. 9A). Two AtAVP genes, AtAVP1 and AtAVP2, did not show significant changes in expression in Col-0 and atvha-d2 mutant (Fig. 9B). The results showed that the inhibition of the AtVHA-d2 expression caused changes in the expression of most members of the AtAHA genes under normal and oxidative stress.

\section{Discussion}

The AtVHA-d1 and AtVHA-d2 genes are highly similar in sequence (Fig. 1A), and it is presumed that they may come from a gene replication event. Moreover, their expression pattern is highly overlapping. The promoter-driven GUS expression analysis showed that the AtVHA-d1 and AtVHA-d2 genes were generally 
expressed in multiple tissues at different developmental stages of Arabidopsis, including all tissues of seedlings, especially the stipule primordia, as well as pollens and embryo sacs (Fig. 2), indicating that they are non-redundant. In addition, the tissue specificity of the expression of AtVHA-d genes is highly consistent with that of AtVHA-c genes reported previously $[15,17]$. VHA-d and VHA-c are important assembly subunits of the complete V-ATPase enzyme [6]. The VHA-d itself does not have a transmembrane domain; it can be located on the membrane by combining with VHA-c [5]. As was expected, confocal observation showed that AtVHA-d2 was mainly localized to the vacuoles (Fig. 3). Furthermore, the localization pattern of AtVHA-d2 was similar to those of AtVHA-c5 [12]. The consistency of the expression pattern and subcellular localization suggest that AtVHA-d2, together with AtVHA-c, may be involved in the assembly of the V-ATPase in the expressed tissues.

Studies have shown that V-ATPase is involved in multiple stress responses $[10,18,19]$. qPCR analysis showed that AtVHA-d2 was significantly induced by multiple stresses, especially oxidative stress (Fig. 4). Phenotypic analysis showed that the relative root length and fresh weight of the atvha-d2 were significantly lower than that of the Col-0 under oxidative stress (Fig. 5). Under normal culture conditions $(1 / 2 \mathrm{MS})$, the $\mathrm{H}^{+}$was influx in the atvha-d2 roots, while $\mathrm{H}_{2} \mathrm{O}_{2}$ treatment caused the $\mathrm{H}^{+}$efflux, which was significantly different from that of Col-0 (Fig. 7). These results suggest that the atvha-d2 is sensitive to oxidative stress, which may be associated with abnormal $\mathrm{H}^{+}$flux in roots. The extrusion of $\mathrm{H}^{+}$in roots is directly regulated by P-ATPase [20]. In Arabidopsis, P-ATPase is encoded by 11 genes, AtAHA1 to AtAHA11, of which AtAHA1 and AtAHA2 are the most highly expressed isoforms [20, 21]. RNA-seq combined with qPCR analysis showed that the expression of AtAHA1 and AtAHA2 in atvha-d2 was significantly higher than that of Col-0 after oxidative stress (Fig. 8E, 9A). The results suggest that the $\mathrm{H}^{+}$ efflux in atvha-d2 roots under oxidative stress (for $24 \mathrm{~h}$ ) may be caused by higher expression of AtAHA1 or AtAHA2. V-ATPase together with P-ATPase and V-PPase co-regulates the $\mathrm{H}^{+}$balance in the plant cells $[1,3]$. Compared to Col-0, the expression of genes encoding the other V-ATPase assembly subunits, PATPase and V-PPase in the atvha-d2 mutant were altered by RNA-seq and qPCR (Fig. 8E, 9A). The result suggests that V-ATPase, P-ATPase, and V-PPase play a synergistic role in $\mathrm{H}^{+}$balance through gene expression regulation. As part of the evidence, the expression of AtVHA-c, AtAVP1, AtAHA1, and AtAHA2 was simultaneously affected in the atsos 1 mutant (SOS1, a plasma membrane $\mathrm{Na}^{+} / \mathrm{H}^{+}$-antiporter) [22].

\section{Conclusions}

In conclusion, our results indicate that AtVHA-d2 plays a role in Arabidopsis in response to oxidative stress by affecting $\mathrm{H}^{+}$flux and AtAHA gene expression.

\section{Methods}

\section{Plant material and growth conditions}


All Arabidopsis thaliana plants used in this study belonged to the Columbia-0 (Col-0) ecotype, including wild-type, T-DNA insertion mutant, and transgenic plants. The AtVHA-d2 T-DNA insertion mutant SAIL_141_G06 (CS806840) was obtained from the Arabidopsis Biological Resource Center (ABRC: http://www.arabidopsis.org/). Homozygous plants were selected by PCR using the specific primers At3g28715-LP, At3g28715-RP, and left-border LB-3. The expression levels of AtVHA-d2 and AtVHA-d1 in mutant SAIL_141_G06 were analyzed by real-time quantitative PCR using their respective primers (AtVHAd1-qF, AtVHA-d1-qR, AtVHA-d2-qF and AtVHA-d2-qR) (Additional file 3: Table S3). The sterilized Arabidopsis seeds were sown on 1/2 Murashige and Skoog (MS) medium. After sowing, the seeds were incubated at $4{ }^{\circ} \mathrm{C}$ for 3 days and then germinated in a growth chamber at $22^{\circ} \mathrm{C}$ under a $12 \mathrm{~h} / 12 \mathrm{~h}$ light/dark photoperiod.

\section{Vector Construction And Arabidopsis Transformation}

To construct proAtVHA-d1:GUS and proAtVHA-d2:GUS, 1644 and 1657 bp of the AtVHA-d1 and AtVHA-d2 promoter regions were amplified using Col-0 genomic DNA and cloned into the HindIII/BamHI or $\mathrm{Kpnl}$ /Xhol sites of pBI121-GUS or pBI121-GUS (modified, more enzyme digestion sites were added) vectors. To construct the AtVHA-d2-GFP fusion genes, the open reading frame (ORF) of AtVHA-d2, without the stop codon, was amplified using PCR and cloned into the Xbal/Kpnl sites of the pBI121-GFP vector. The specific primers used in this study are listed in Table S1. The constructs were stably transformed into Arabidopsis via the Agrobacterium tumefaciens-mediated floral dip method [23]. The T3 transgenic plants were identified by reverse transcription PCR (RT-PCR).

\section{Confocal Laser Scanning Microscopy}

Roots of transgenic Arabidopsis seedlings stably expressing AtVHA-d2-GFP were washed twice with liquid 1/2 MS medium immediately before visualizing via confocal laser scanning microscopy (Nikon, A1, Japan). GFP signals were detected using a 500-530 nm emission filter.

\section{Histochemical $\beta$-glucuronidase Staining}

Seedlings and different organs of transgenic Arabidopsis (proAtVHA-d1:GUS and proAtVHA-d2:GUS) were immersed in the staining buffer ( $100 \mathrm{mM}$ sodium phosphate, $\mathrm{pH} 7.0,10 \mathrm{mM}$ EDTA, $0.5 \mathrm{mM} \mathrm{K}_{3}\left[\mathrm{Fe}(\mathrm{CN})_{6}\right]$, $0.5 \mathrm{mM} \mathrm{K}_{4}\left[\mathrm{Fe}(\mathrm{CN})_{6}\right], 0.1 \%$ Triton X-100) supplemented with $0.5 \mathrm{mM} \mathrm{5-bromo-4-chloro-3-indolyl- \beta -d-}$ glucuronide (X-Gluc) for $12 \mathrm{~h}$ at $37^{\circ} \mathrm{C}$. Chlorophyll in green parts was removed by repeated washing in $95 \%$ ethanol.

\section{Quantitative Real-time Pcr Analyses}


For abiotic stress treatments, 7-day-old Arabidopsis seedlings were exposed to $150 \mathrm{mM} \mathrm{NaCl}, 300 \mathrm{mM}$ mannitol, $5 \mathrm{mM} \mathrm{H}_{2} \mathrm{O}_{2}, 100 \mu \mathrm{M}$ abscisic acid (ABA), cold $\left(4^{\circ} \mathrm{C}\right)$, or heat $\left(37^{\circ} \mathrm{C}\right)$. The seedlings were collected at different time points $(0,3,6,12$, and $24 \mathrm{~h})$ after treatment, and then frozen immediately in liquid nitrogen for RNA extraction.

Total RNA was extracted using the RNAprep pure plant kit (Tiangen, Beijing, China), and cDNA was synthesized from $1 \mu \mathrm{g}$ total RNA using the M-MLV RTase cDNA synthesis kit (TaKaRa, Shiga, Japan), according to the manufacturer's instructions. qPCR was performed on a Mx3000P QPCR system (Agilent Technologies, Palo Alto, CA, USA). The Arabidopsis AtActin2 gene was used as an internal control. Three biological repeats and three technical repeats were performed for qPCR analysis. The primers used in this study are shown in Additional file 4: Table S3.

\section{Stress Tolerant Phenotype}

For stress tolerant assay, the 30 seeds of Col- 0 and the atvha-d 2 mutant were treated at $4{ }^{\circ} \mathrm{C}$ for 3 days and then grown vertically on $1 / 2 \mathrm{MS}$ (control) or $1 / 2 \mathrm{MS}$ medium supplemented with different concentrations of $\mathrm{NaCl}(75$ and $100 \mathrm{mM}), \mathrm{H}_{2} \mathrm{O}_{2}$ (1 and $2 \mathrm{mM}$ ), and mannitol (175 and $\left.200 \mathrm{mM}\right)$. After 14 days, seedling phenotypes were photographed, and the root length, relative root length and fresh weight of the seedlings were measured.

\section{Net $\mathrm{H}^{+}$Flux Measurement}

Net $\mathrm{H}^{+}$flux was measured using the Non-invasive Micro-test Technology (NMT100 Series, YoungerUSA LLC, Amherst, MA, USA) as described previously $[12,24]$. Seven-day-old seedlings of Col-0 and the atvhad2 mutant were grown on 1/2 MS medium, and were exposed to mannitol (200 mM), $\mathrm{NaCl}(100 \mathrm{mM})$, and $\mathrm{H}_{2} \mathrm{O}_{2}(2 \mathrm{mM})$ for $24 \mathrm{~h}$. Root segments were immobilized in the measuring solution $(0.1 \mathrm{mM} \mathrm{KCl}, 0.1 \mathrm{mM}$ $\mathrm{CaCl}_{2}, 0.1 \mathrm{mM} \mathrm{MgCl}_{2}, 0.5 \mathrm{mM} \mathrm{NaCl}$, and $0.3 \mathrm{mM} \mathrm{MES}, \mathrm{pH}$ 5.8) to measure the $\mathrm{H}^{+}$flux. Six biological repeats were performed for each analysis.

\section{Rna-seq And Degs Analysis}

Seedlings of Col-0 and the atvha-d2 mutant were treated in 1/2 MS medium supplemented with $\mathrm{H}_{2} \mathrm{O}_{2}$ ( $2 \mathrm{mM}$ ) for 0,12 , and $24 \mathrm{~h}$. Total RNA from the seedlings was isolated using TRIzol reagent (Invitrogen, Carlsbad, CA, USA). Subsequently, the RNA samples were sent to the Beijing Genomic Institute (BGI, Shenzhen, China) for RNA-seq.

DEGs were screened with a false discovery rate (FDR) threshold of 0.01 and an absolute log2 ratio of 1. All DEGs were mapped to each term of KEGG module from KEGG databases, and significant pathways were defined based on a corrected $P$ value $\leq 0.05$. 


\section{Abbreviations}

V-ATPase: vacuolar-type $\mathrm{H}^{+}$-ATPase; P-ATPase: plasma membrane $\mathrm{H}^{+}$-ATPase; V-PPase: vacuolar $\mathrm{H}^{+}$pyrophosphatase; TGN/EE: trans-Golgi network/early endosome; det3: deetiolated3; AtSOS2:

salt overly sensitive 2; GUS: $\beta$-glucuronidase; GFP: green fluorescent protein; qPCR: quantitative real-time PCR; DEGs: differentially expressed genes; RNA-seq: RNA sequencing; Col-0: Columbia-0; MS: Murashige and Skoog; RT-PCR: reverse transcription PCR.

\section{Declarations}

Competing interests

The authors declare that they have no conflict of interest.

\section{Funding}

This work was supported by the Zhejiang Science and Technology Major Program on Agricultural New Variety Breeding of China (grant no. 2016C02056-1), the State Key Laboratory of Subtropical Silviculture of China (grant no. KF201707), Fundamental Research Funds for the Central Universities of China (grant no. 2572016CA14), Heilongjiang Province Government Postdoctoral Science Foundation of China (grant no. LBH-Q18008), and the 'Academic backbone' Project of Northeast Agricultural University of China (grant no. 18XG08).

Authors' contributions

SF, SL, and YB designed the experiments. SF, YP, EL and HM performed the experiments. KQ and AZ analyzed the data. SF wrote the article. All authors read and approved the final manuscript.

Availability of data and materialss

The relevant data sets supporting the results of this article are included within the article and its additional files.

Ethics approval and consent to participate

Not applicable.

Consent for publication

Not applicable.

Acknowledgements

We thank reviewers for checking our manuscript and the editors for editing the paper.

\section{References}

1.

Gaxiola RA, Palmgren MG, Schumacher K. Plant proton pumps. FEBS Lett. 2007;581(12):2204-14. 2. 
Schumacher K. Endomembrane proton pumps: connecting membrane and vesicle transport. Curr Opin Plant Biol. 2006;9(6):595-600.

3.

Schumacher K. pH in the plant endomembrane system-an import and export business. Curr Opin Plant Biol. 2014;22C:71-6.

4.

Shen J, Zeng Y, Zhuang X, Sun L, Yao X, Pimpl P, Jiang L. Organelle pH in the Arabidopsis endomembrane system. Mol Plant. 2013;6(5):1419-37.

5 .

Forgac M. Vacuolar ATPases: rotary proton pumps in physiology and pathophysiology. Nat Rev Mol Cell Biol. 2007;8(11):917-29.

6.

Schumacher K, Krebs M. The V-ATPase: small cargo, large effects. Curr Opin Plant Biol. 2010;13(6):72430 .

7.

Dettmer J, Hong-Hermesdorf A, Stierhof YD, Schumacher K. Vacuolar $\mathrm{H}^{+}$-ATPase activity is required for endocytic and secretory trafficking in Arabidopsis. Plant Cell. 2006;18(3):715-30.

8.

Krebs M, Beyhl D, Gorlich E, Al-Rasheid KA, Marten I, Stierhof YD, Hedrich R, Schumacher K. Arabidopsis VATPase activity at the tonoplast is required for efficient nutrient storage but not for sodium accumulation. Proc Natl Acad Sci U S A. 2010;107(7):3251-6.

9.

Luo Y, Scholl S, Doering A, Zhang Y, Irani NG, Rubbo SD, Neumetzler L, Krishnamoorthy P, Van Houtte I, Mylle E, et al. V-ATPase activity in the TGN/EE is required for exocytosis and recycling in Arabidopsis. Nat Plants. 2015;1:15094.

10.

Batelli G, Verslues PE, Agius F, Qiu Q, Fujii H, Pan S, Schumaker KS, Grillo S, Zhu JK. SOS2 promotes salt tolerance in part by interacting with the vacuolar $\mathrm{H}^{+}$-ATPase and upregulating its transport activity. Mol Cell Biol. 2007;27(22):7781-90.

11.

Schumacher K, Vafeados D, McCarthy M, Sze H, Wilkins T, Chory J. The Arabidopsis det3 mutant reveals a central role for the vacuolar $\mathrm{H}(+)$-ATPase in plant growth and development. Genes Dev. 1999;13(24):3259-70.

12.

Zhou A, Liu E, Ma H, Feng S, Gong S, Wang J. NaCl-induced expression of AtVHA-c5 gene in the roots plays a role in response of Arabidopsis to salt stress. Plant Cell Rep. 2018;37(3):443-52.

13.

Milgrom E, Diab H, Middleton F, Kane PM. Loss of vacuolar proton-translocating ATPase activity in yeast results in chronic oxidative stress. J Biol Chem. 2007;282(10):7125-36.

14. 
Nishikawa H, Miyazaki T, Nakayama H, Minematsu A, Yamauchi S, Yamashita K, Takazono T, Shimamura S, Nakamura S, Izumikawa K, et al: Roles of vacuolar $\mathrm{H}^{+}$-ATPase in the oxidative stress response of Candida glabrata. FEMS Yeast Res. 2016, 16(5).

15.

Zhou A, Bu Y, Takano T, Zhang X, Liu S. Conserved V-ATPase c subunit plays a role in plant growth by influencing V-ATPase-dependent endosomal trafficking. Plant Biotechnol J. 2016;14(1):271-83.

16.

Sze H, Schumacher K, Muller ML, Padmanaban S, Taiz L. A simple nomenclature for a complex proton pump: VHA genes encode the vacuolar H(+)-ATPase. Trends Plant Sci. 2002;7(4):157-61.

17.

Padmanaban S, Lin X, Perera I, Kawamura Y, Sze H. Differential expression of vacuolar H-ATPase subunit $c$ genes in tissues active in membrane trafficking and their roles in plant growth as revealed by RNAi. Plant Physiol. 2004;134(4):1514-26.

18.

Liu N, Ni Z, Zhang H, Chen Q, Gao W, Cai Y, Li M, Sun G, Qu YY. The gene encoding subunit A of the vacuolar $\mathrm{H}(+)$-ATPase from cotton plays an important role in conferring tolerance to water deficit. Front Plant Sci. 2018;9:758.

19.

Zhao Q, Zhao YJ, Zhao BC, Ge RC, Li M, Shen YZ, Huang ZJ. Cloning and functional analysis of wheat V$\mathrm{H}^{+}$-ATPase subunit genes. Plant Mol Biol. 2009;69(1-2):33-46.

20.

Haruta M, Burch HL, Nelson RB, Barrett-Wilt G, Kline KG, Mohsin SB, Young JC, Otegui MS, Sussman MR. Molecular characterization of mutant Arabidopsis plants with reduced plasma membrane proton pump activity. J Biol Chem. 2010;285(23):17918-29.

21.

Baxter I, Tchieu J, Sussman MR, Boutry M, Palmgren MG, Gribskov M, Harper JF, Axelsen KB. Genomic comparison of P-type ATPase ion pumps in Arabidopsis and rice. Plant Physiol. 2003;132(2):618-28. 22.

Oh DH, Lee SY, Bressan RA, Yun DJ, Bohnert HJ. Intracellular consequences of SOS1 deficiency during salt stress. J Exp Bot. 2010;61(4):1205-13.

23.

Clough SJ, Bent AF. Floral dip: a simplified method for Agrobacterium-mediated transformation of Arabidopsis thaliana. Plant J. 1998;16(6):735-43.

24.

Sun J, Chen S, Dai S, Wang R, Li N, Shen X, Zhou X, Lu C, Zheng X, Hu Z, et al. NaCl-induced alternations of cellular and tissue ion fluxes in roots of salt-resistant and salt-sensitive poplar species. Plant Physiol. 2009;149(2):1141-53.

\section{Figures}


AtVHA-d1 (NP_189512)

AtVHA-d2 (NP_189513)

AtVHA-d1 (NP_189512)

AtVHA-d2 (NP_189513)

AtVHA-d1 (NP 189512)

AtVHA-d2 (NP_189513)

AtVHA-d1 (NP_189512)

AtVHA-d2 (NP_189513)

AtVHA-d1 (NP_189512)

AtVHA-d2 (NP_189513)

AtVHA-d1 (NP_189512)

AtVHA-d2 (NP_189513)

AtVHA-d1 (NP_189512)

AtVHA-d2 (NP_189513)

AtVHA-d1 (NP_189512)

AtVHA-d2 (NP_189513)

AtVHA-d1 (NP_189512)

AtVHA-d2 (NP_189513)
MYGFE ALTFN I HG G YLA I VRGHRAGLLT TADYNNLCQCE

MYGFEALTFN I HGG YLEA I VRGHRAGLLTTADYNNLCQCE $\downarrow$

NLDDIKMHLSATKYGSYLQNEP SPLHTT TI VEKCTLKLVD 80

NLDD I KMHLSATKYGPYLQNEPSPLHTTT I VEKCTLKLVD 80

DYKHML CQATE PMST FLE Y I RYGHM I DNVVL I VTGTLHER 120

DYKHMLCQATEPMSTFLEY I RYGHM I DNVVL I VTGTLHER 120

DVQEL I E K CHPLGMFDS I A TLAVAQNMRE L YRLVLVDT PL 160

DVQEL I E KCHPLGMFDS I ATLAVAQNMRE L YRLVLVDTPL 160

I

APYFSECLT SEDLDDMN I E I MRNTLYKA YLE DF YKFCQKL 200

APYFSECLT SEDLDDMN I E I MRNTLYKAYLEDFYNFCQKL 200

GG AT AE I MSDLLA FEADRRAVN I T I N S I G T E L TREDRKKL 240

GGATAE I MSDLLAFEADRRAVN I T I N S I G TELTREDRKKL 240

Y SNFGLLYPYGHE E LA I CE D I DQVRGVMEKYPPYQA I F SK 280

YSNFGLLYPYGHEELA I CED I DQVRGVMEKYPPYQA I F SK 280

MS Y GE SQML DKA F YE E E VRRLCLAFEQQFH Y AVF F A YMRL 320 MSYGE SQMLDKAFYEEEVRRLCLAFEQQFHYAVFFAYMRL 320

REQE I RNLMW I SE CVAQNQKSR I HD SVVYMF 351

REQE I RNLMW I SECVAQNQKSR I HDSVVYMF 351

\section{B TMHMM posterior probabilities for WEBSEQUENCE}

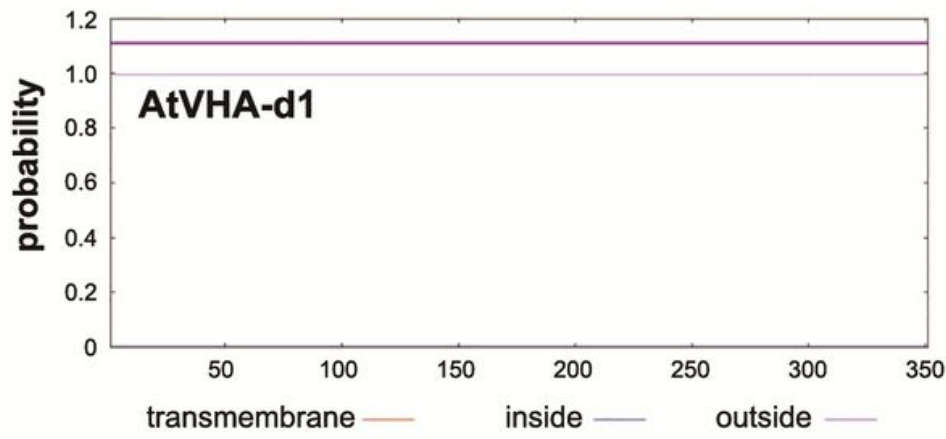

TMHMM posterior probabilities for WEBSEQUENCE

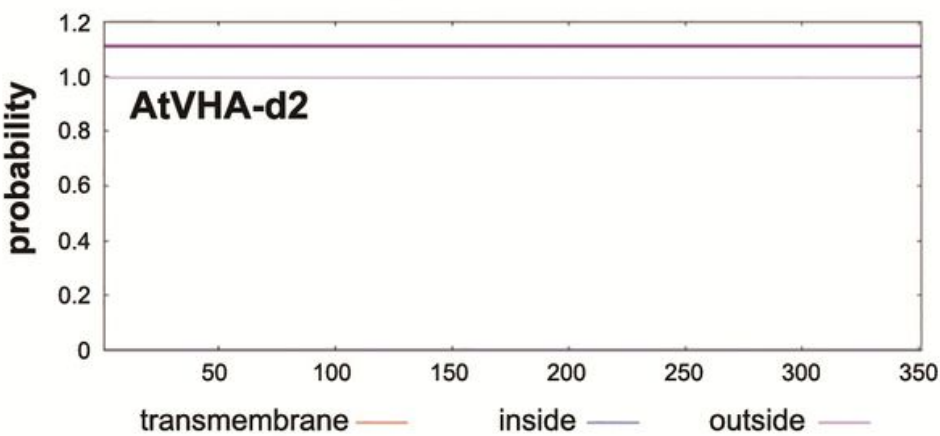

Figure 1

Sequence analysis of AtVHA-d1 and AtVHA-d2 proteins. (A) Amino acid sequence alignment of AtVHA-d1 and AtVHA-d2. The arrows indicate two different amino acids. (B) Transmembrane domain prediction of AtVHA-d1 and AtVHA-d2. 


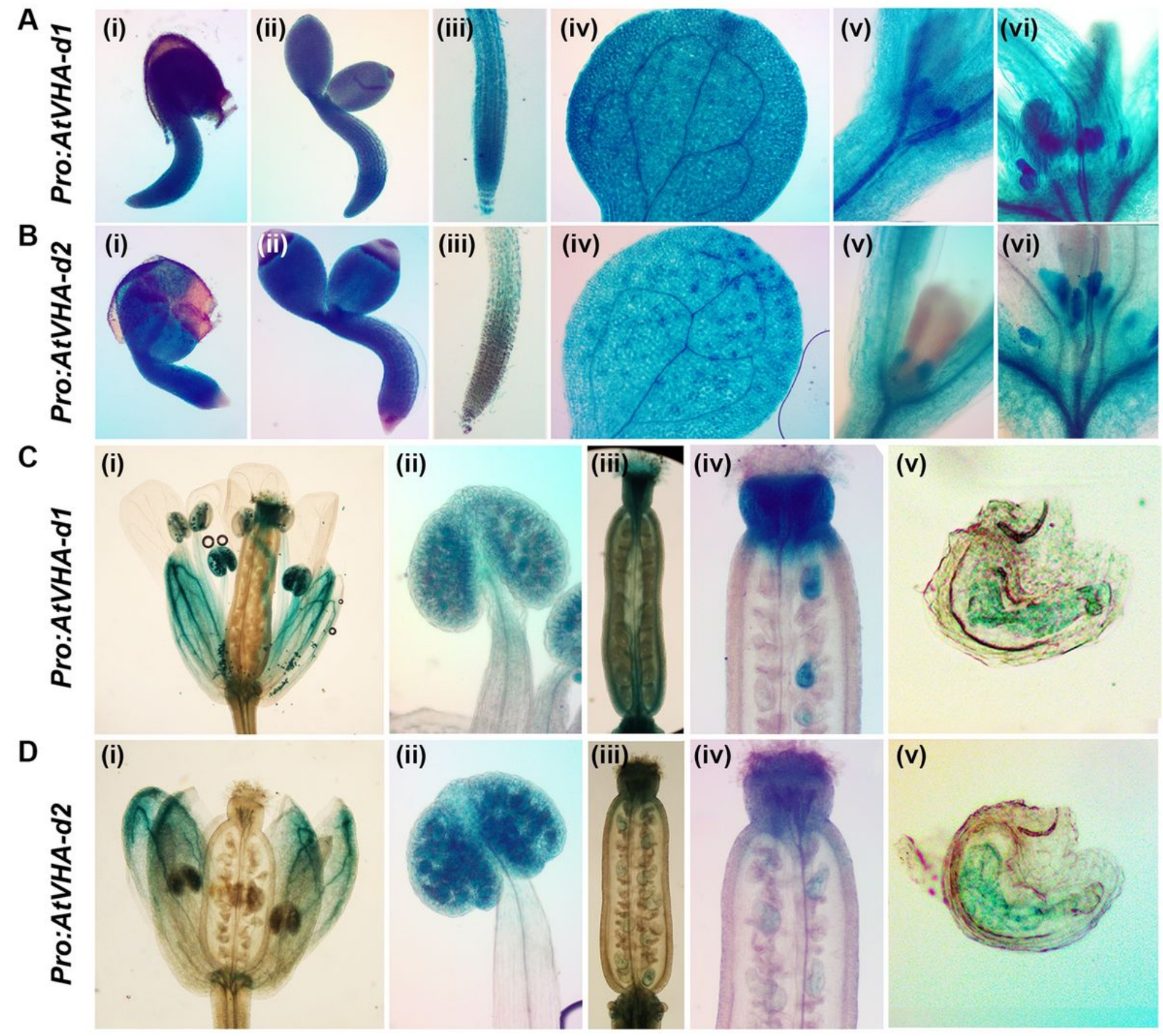

Figure 2

AtVHA-d1 and AtVHA-d2 genes promoter-GUS expression in Arabidopsis. Histochemical GUS staining was carried out at different development stages and in various tissues of AtVHA-d1 and AtVHA-d2 genes promoter-GUS transgenic Arabidopsis plants. ProAtVHA-d1:GUS (A) and ProAtVHA-d2:GUS (B) expression in all tissues of the seedlings ( $\mathrm{i}$ and ii), root (iii), leaf (iv), and stipule primordia ( $\mathrm{v}$ and vi); ProAtVHAd1:GUS (C) and ProAtVHA-d2:GUS (D) expression in the sepal (i), anther (ii), base and top of the silique (iii and iv), and embryo sac (v). 


\section{AtVHA-d2-GFP}

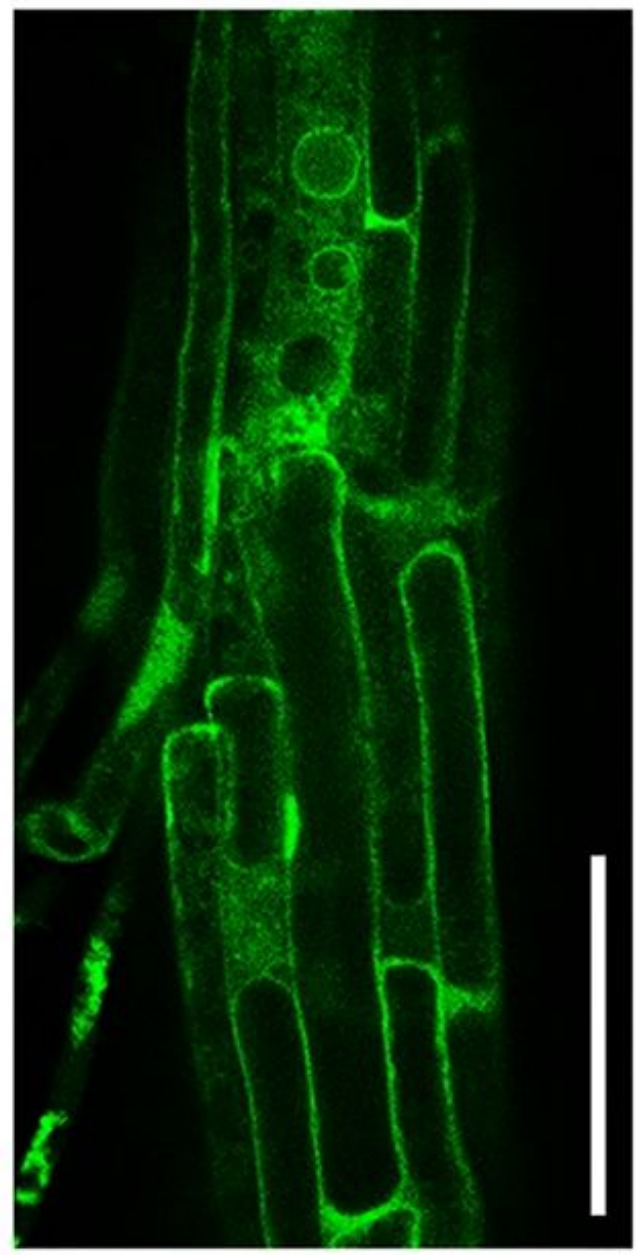

Bright field

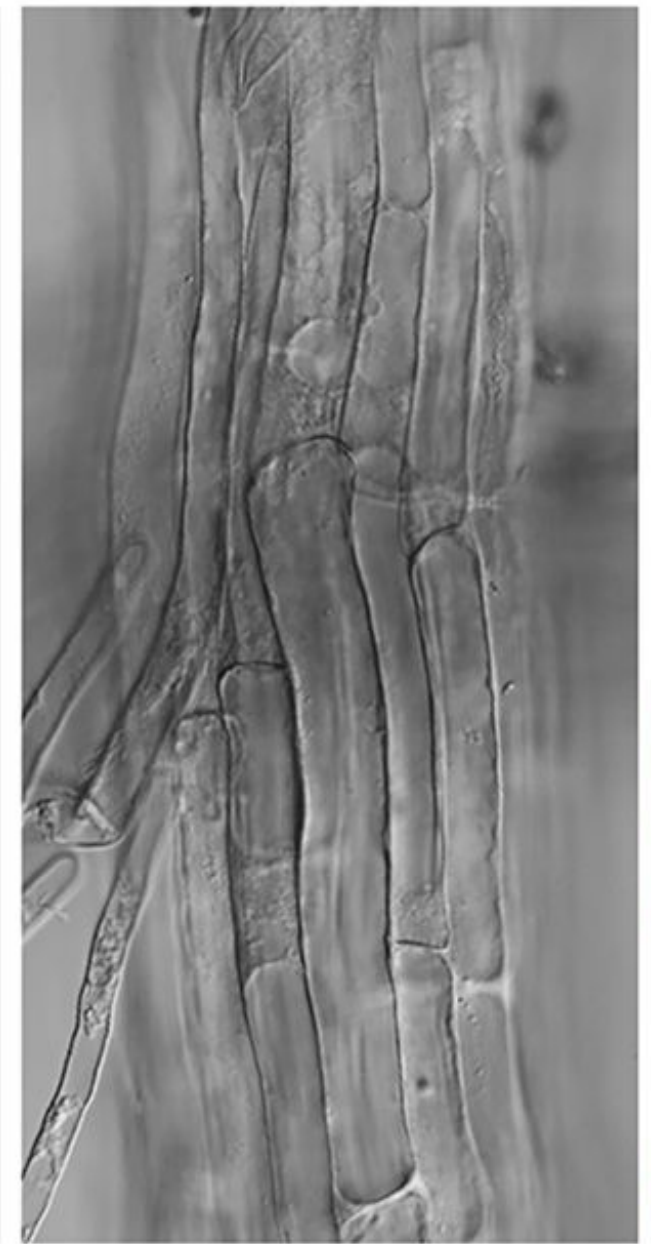

Merge

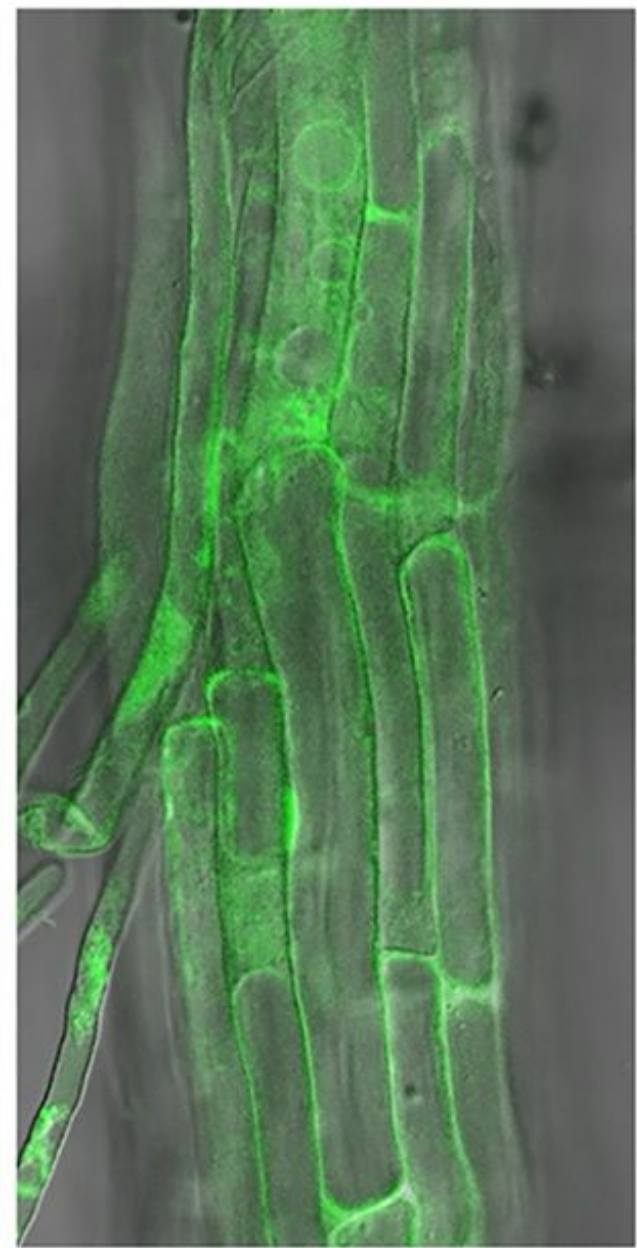

Figure 3

Subcellular localization of AtVHA-d2-GFP in Arabidopsis. GFP fluorescence is green. Merge was created by merging the GFP and bright field images. Scale bar $=50 \mu \mathrm{m}$.
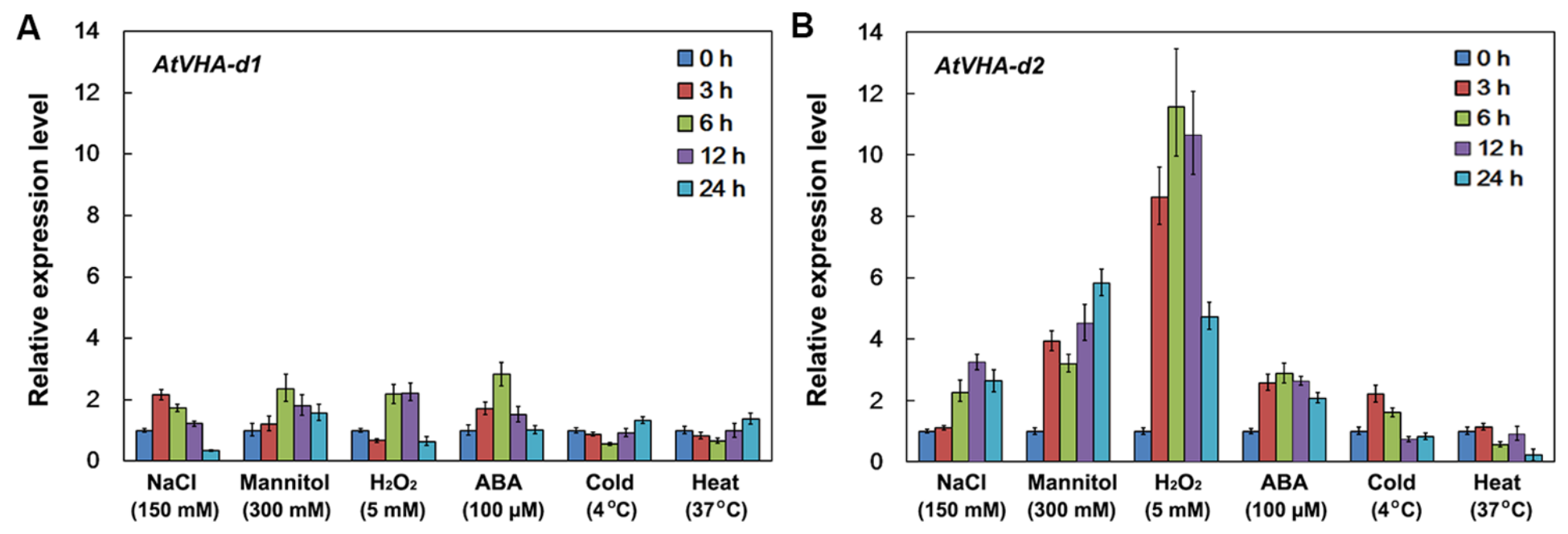

Figure 4 
Expression analysis of AtVHA-d1 and AtVHA-d2 genes under multiple stresses. Ten-day-old Arabidopsis seedlings were treated with $150 \mathrm{mM} \mathrm{NaCl}, 300 \mathrm{mM}$ mannitol, $5 \mathrm{mM} \mathrm{H} 2 \mathrm{O} 2,100 \mu \mathrm{M} \mathrm{ABA}$, and stored at 4 ${ }^{\circ} \mathrm{C}$ (cold) or $37{ }^{\circ} \mathrm{C}$ (heat) for $0,3,6,12$, and $24 \mathrm{~h}$. The expression of AtVHA-d1 (A) and AtVHA-d2 (B) genes were investigated by qPCR, respectively. The AtActin2 gene was used as an internal control, and the transcript level in untreated seedlings was set as 1.0. Error bars represent the $S D(n=3)$.

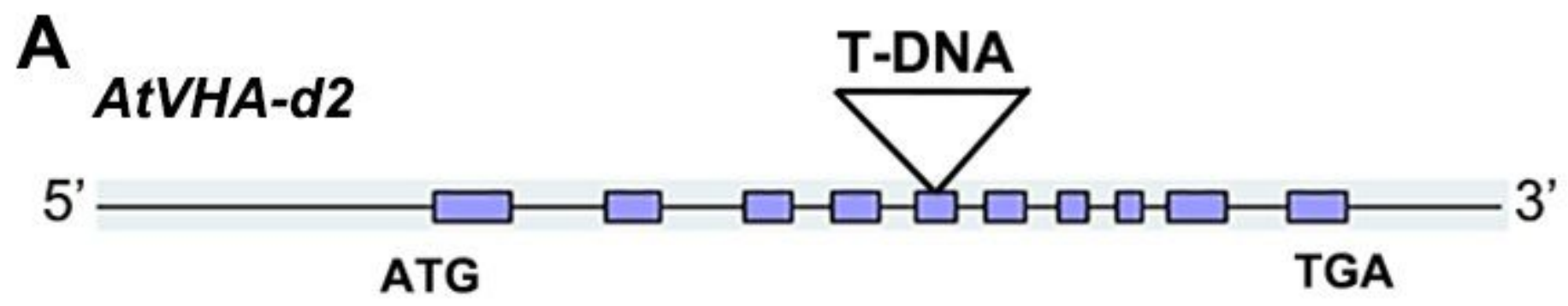

B

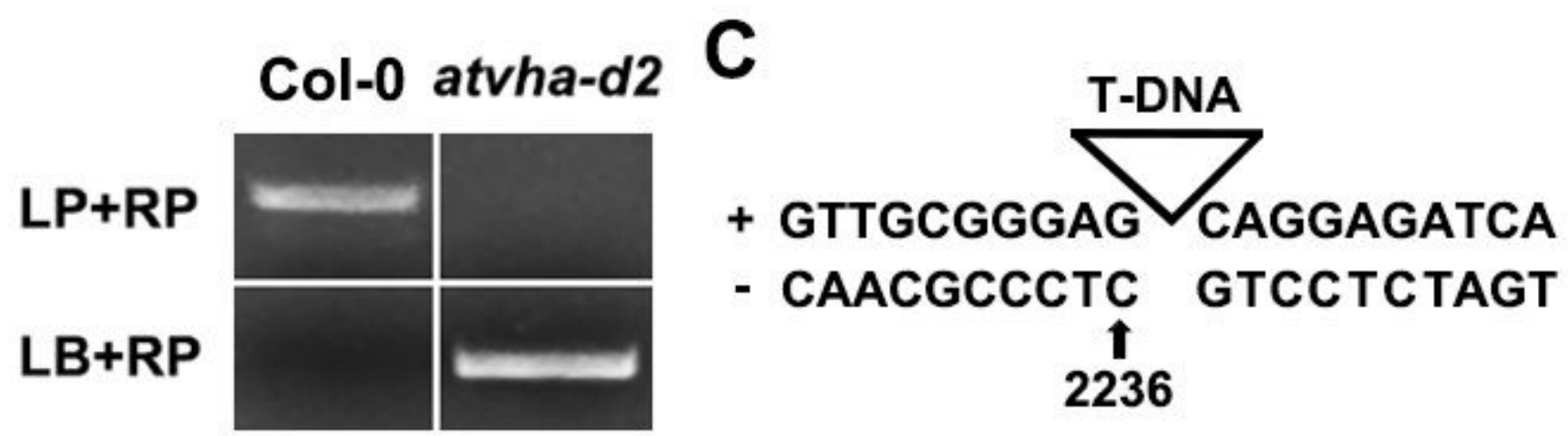

D

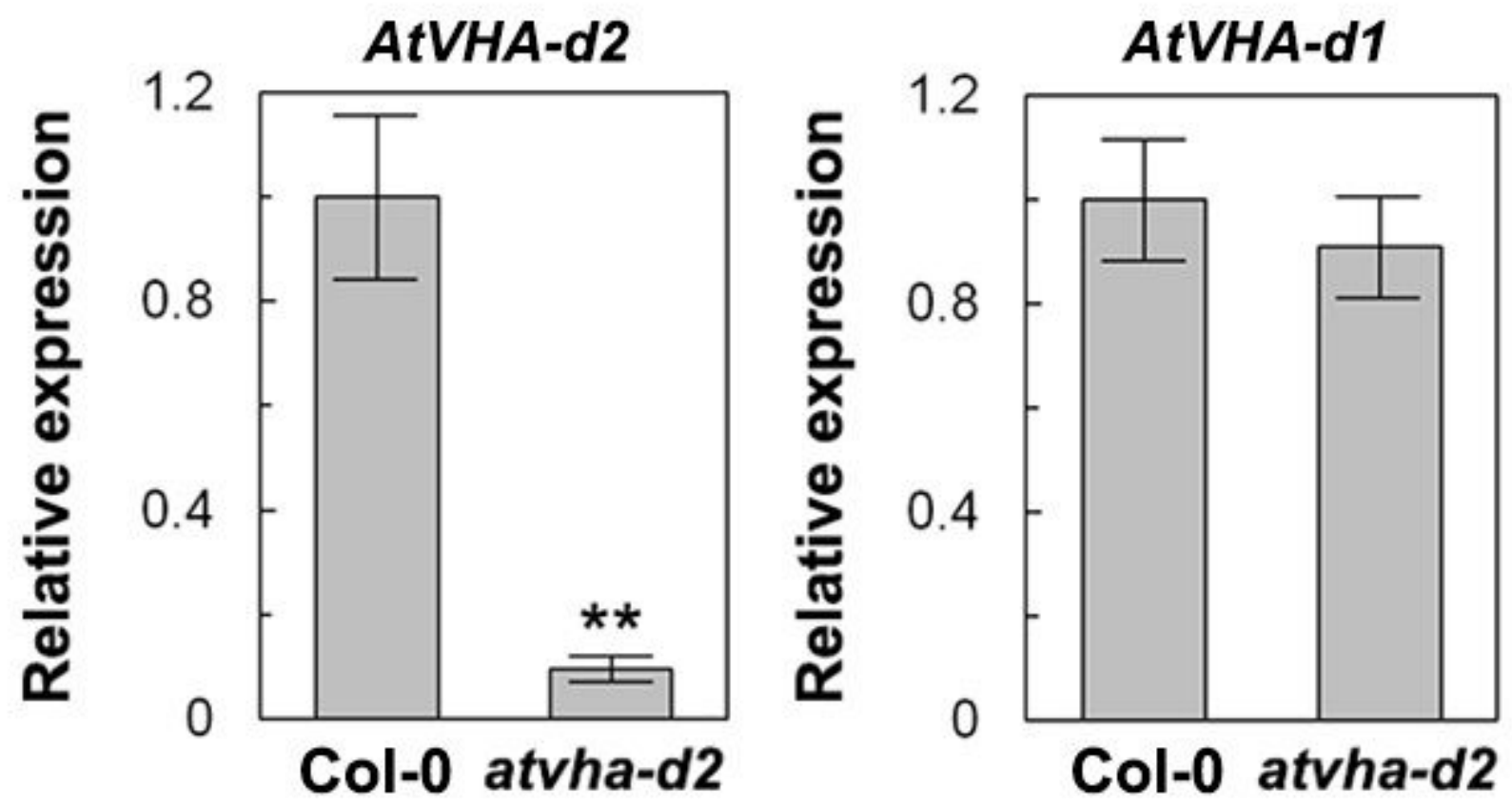

Figure 5

Identification of the Arabidopsis atvha-d2 mutant. Schematic representation of the AtVHA-d2 gene (A) and genotyping (genomic DNA) (B). Original PCR detection pictures are shown in the Figure S1. (C) The position of the T-DNA insertion in the atvha-d2 mutant. (D) Relative expression (mRNA) analysis of 
AtVHA-d2 and AtVHA-d1 genes in the atvha-d2 mutant by qPCR, respectively. Asterisks indicate a significant difference between Col-0 and atvha-d2 plants (**P $<0.01$; Student's t test).
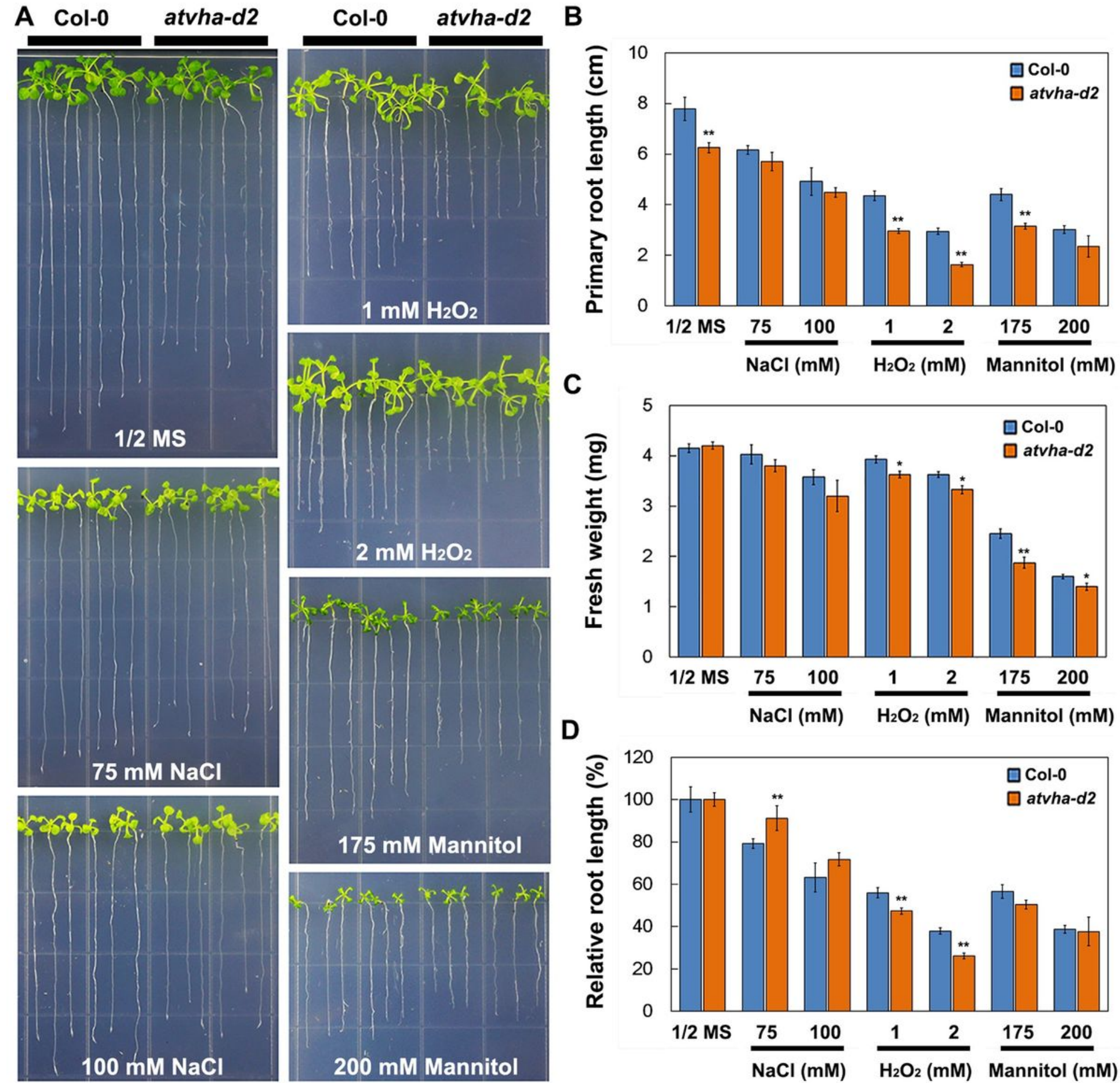

C

D
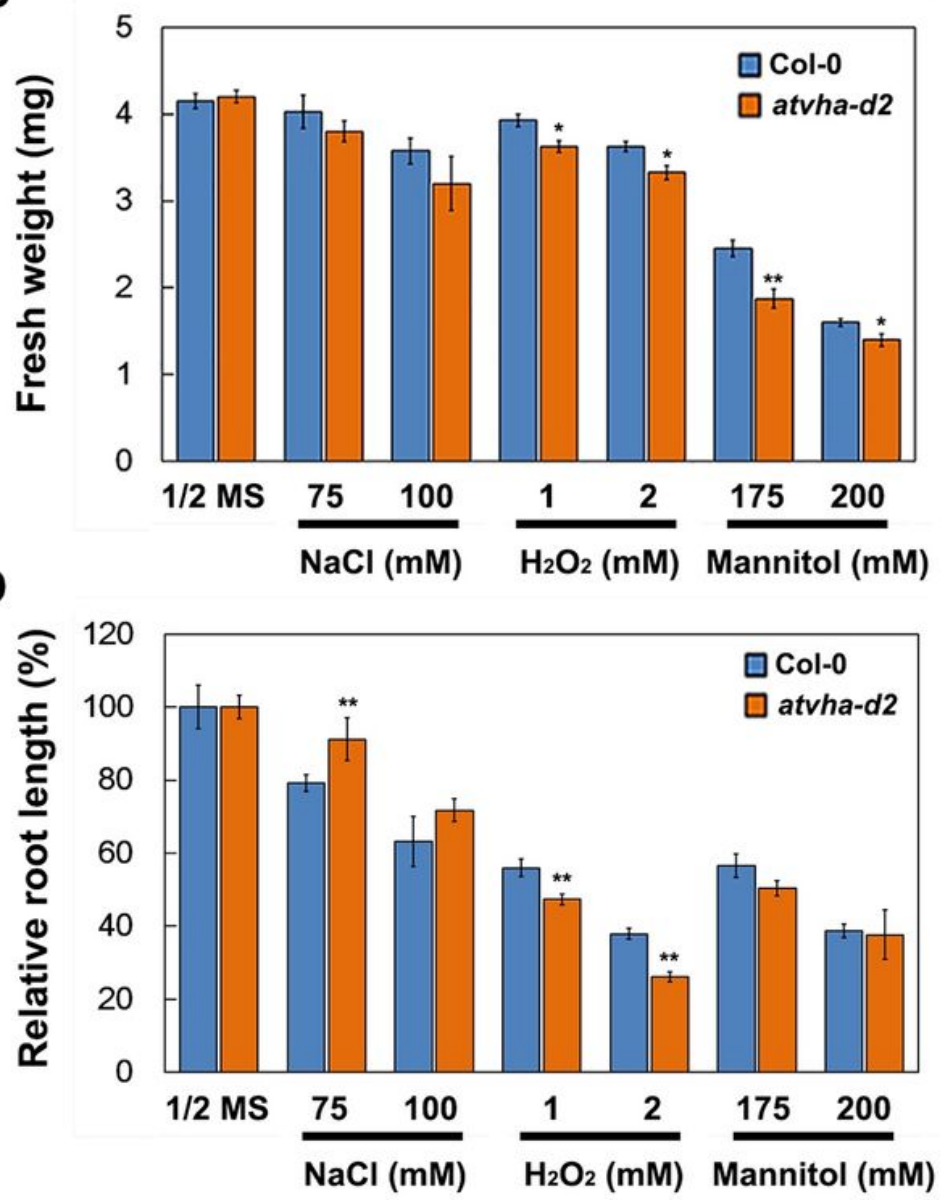

Figure 6

Comparison of phenotypes of the Col-0 and the atvha-d2 mutant under multiple stresses. Phenotypes (A), primary root length (B), relative root length (C), and fresh weight (D) of the Col-0 and the atvha-d2 mutant grown on vertical plates containing 1/2 MS or 1/2 MS medium with $\mathrm{NaCl}$ (75 and $100 \mathrm{mM}$ ), $\mathrm{H} 2 \mathrm{O} 2$ (1 and $2 \mathrm{mM}$ ), and mannitol (175 and $200 \mathrm{mM}$ ) for 14 days. Asterisks indicate a significant difference between Col-0 and atvha-d2 plants (*P $<0.05 ; * * P<0.01$; Student's t test). 
A
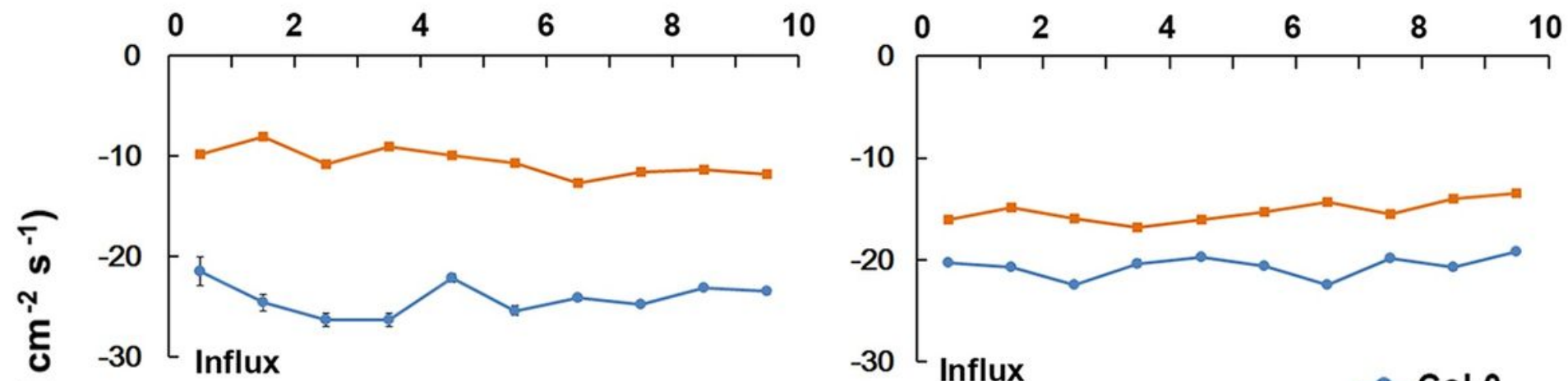

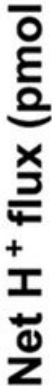

-30 Influx

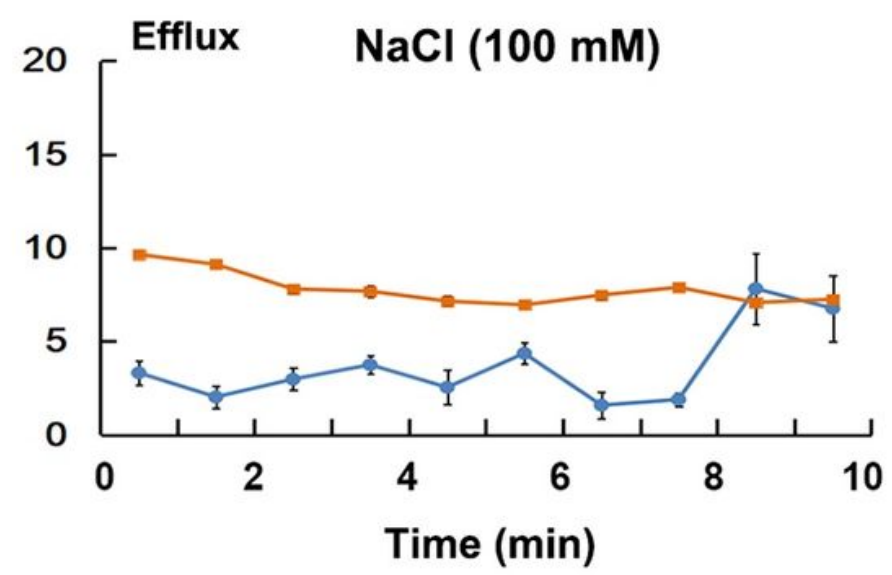

B

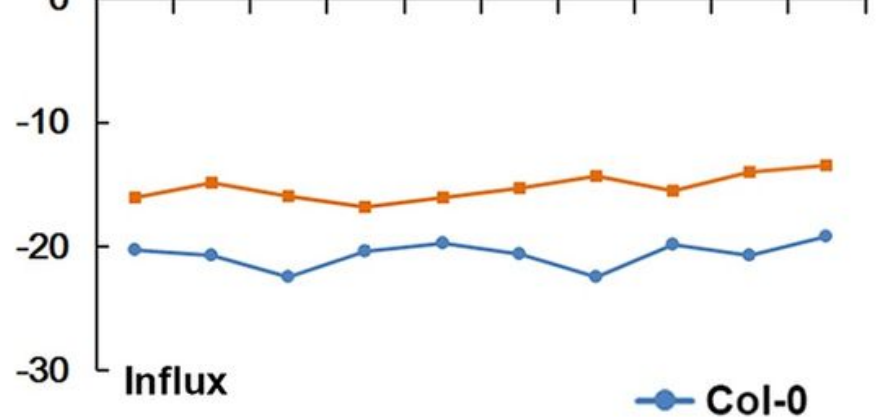
atvha-d2

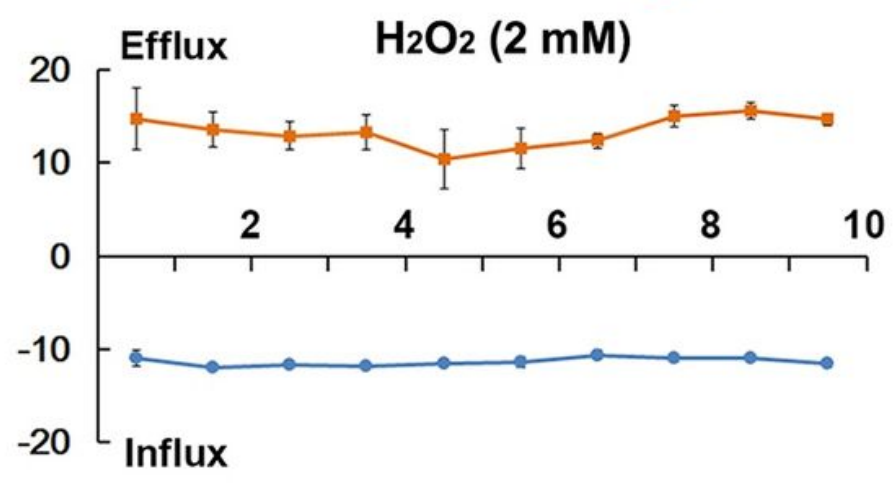

Time (min)
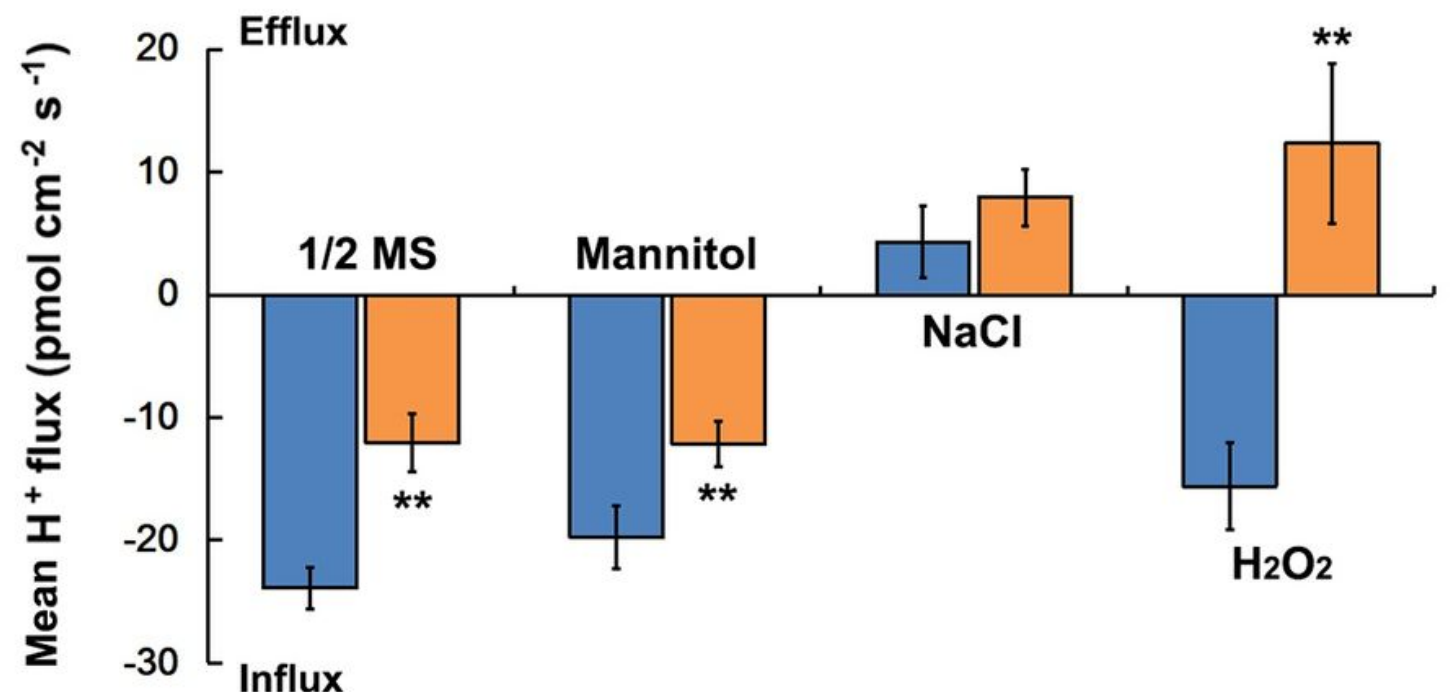

Col-0

$\mathrm{H}_{2} \mathrm{O}_{2}$

Figure 7

$\mathrm{Net} \mathrm{H}+$ flux in the roots of the Col-0 and the atvha-d2 mutant under multiple stresses. Net $(A)$ and mean (B) $\mathrm{H}+$ flux in root elongation zone of the Col- 0 and atvha-d2 seedlings (7-day-old) treated in $1 / 2 \mathrm{MS}$ and 1/2 MS medium with mannitol (200 mM), $\mathrm{NaCl}(100 \mathrm{mM})$, and H2O2 (2 mM) for $24 \mathrm{~h}$. Continuous flux was recorded for $10 \mathrm{~min}$. Mean $\mathrm{H}+$ flux from six samples $(\mathrm{n}=6)$. Asterisks indicate a significant difference between Col-0 and atvha-d2 plants ( ${ }^{\star *} \mathrm{P}<0.01$; Student's $t$ test). 
A

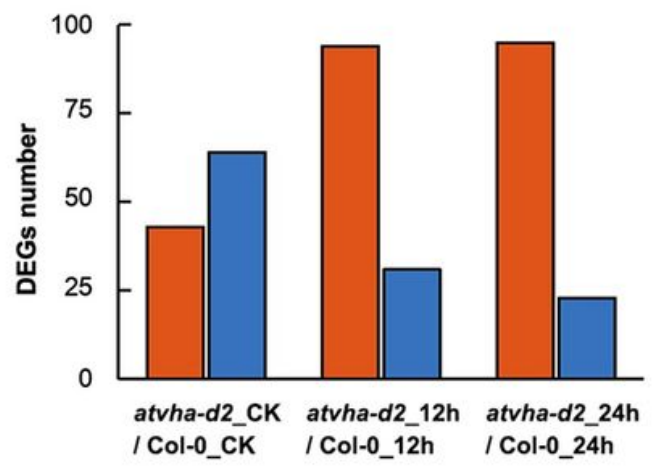

C

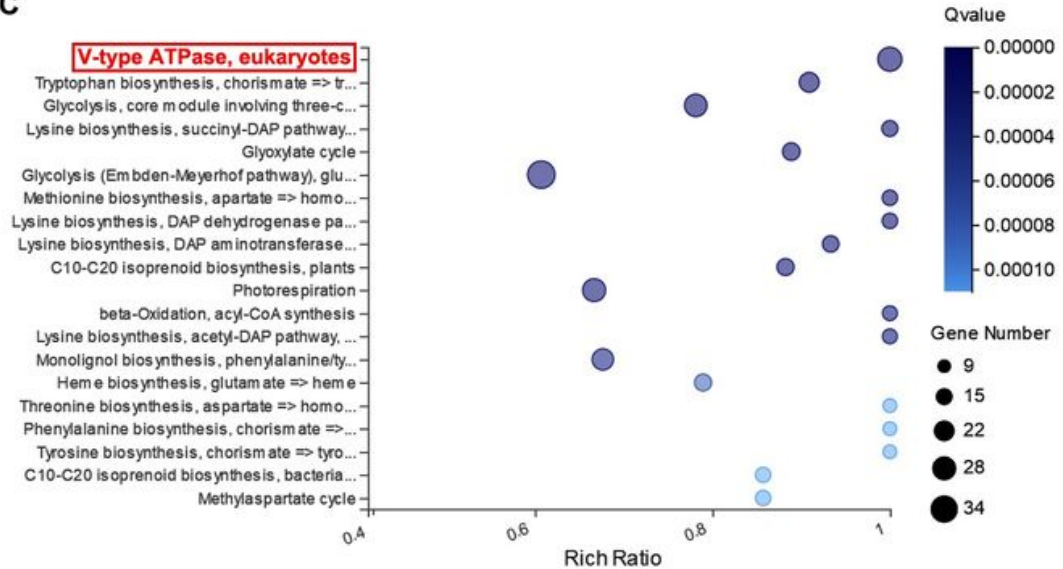

E

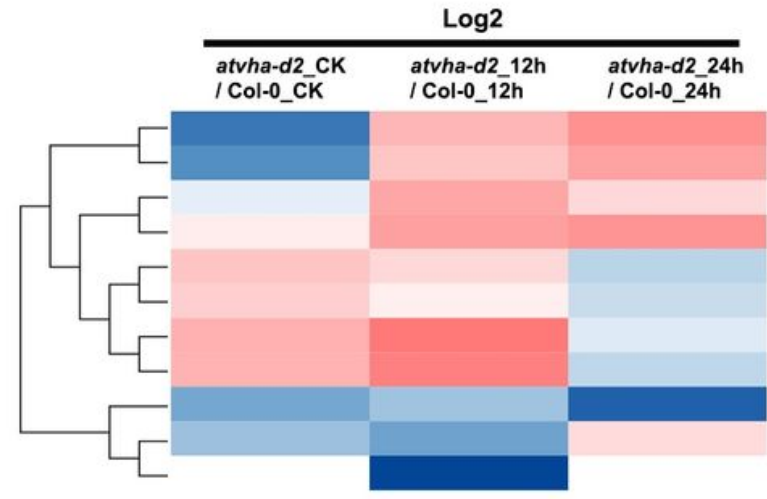

B

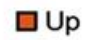

口Down
atvha-d2_CK I Col-0_CK

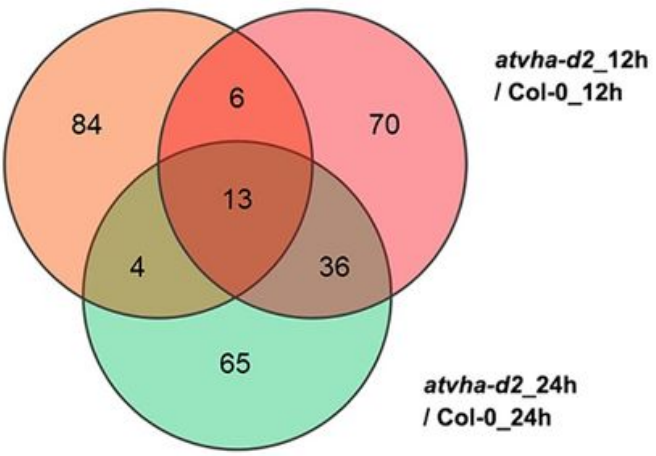

Log2

D atvha-d2 CK atvha-d2 12h atvha-d2 24h ICol-0_CK /Col-0_12h / Col-0_24h

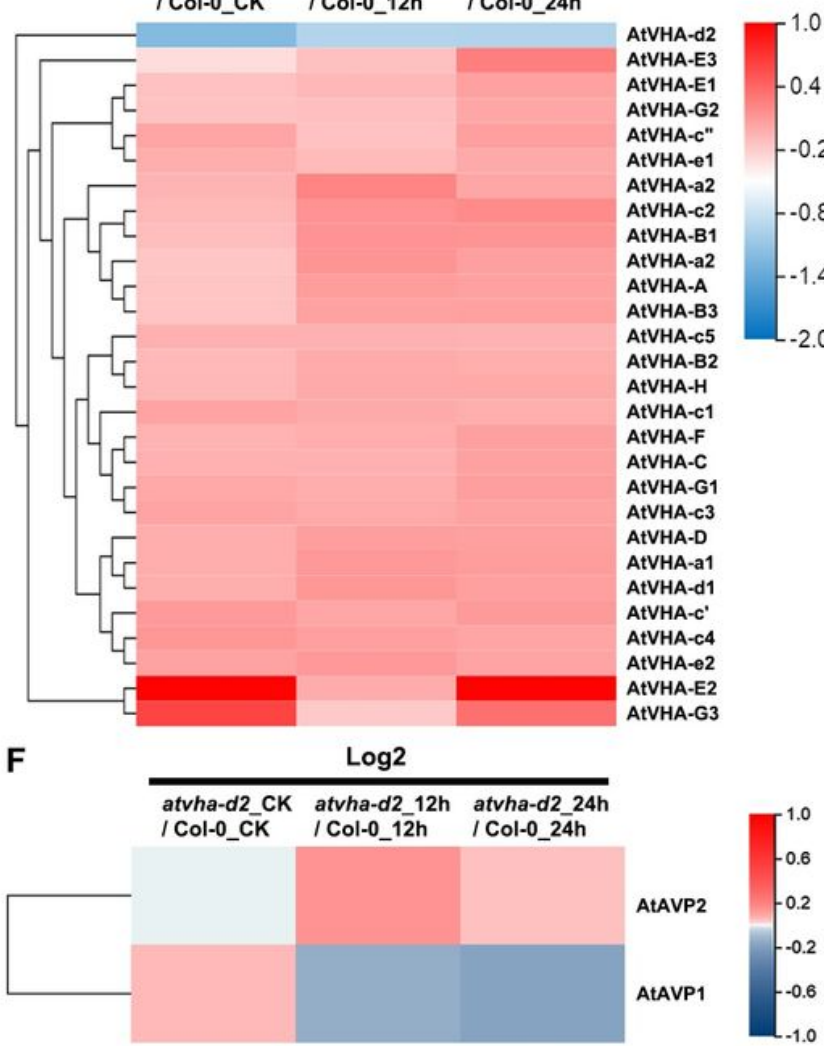

Figure 8

RNA-seq analysis of differentially expressed genes (DEGs) between Col-0 and the atvha-d2 mutant under normal and oxidative stress. The number (A) and Venn diagram (B) of DEGs between Col-0 and the atvhad2 mutant under normal and oxidative stress. DEG screening thresholds using false discovery rate $\leq 0.01$ and the absolute value of log2Ratio $\geq 1$. (C) KEGG module enrichment analysis of DEGs and their interaction genes. The rich factor is the ratio of the number of DEGs annotated in a given module term to the number of all genes annotated in the module term. The $Q$ value is the corrected $P$ value and ranges from 0 to 1, and a lower $Q$ value indicates greater intensity. Expression of V-ATPase subunits (AtVHA) (D), P-ATPase (AtAHA) (E), and V-PPase (AtAVP) (F) genes in Col-0 and the atvha-d2 mutant under normal and oxidative stress. Red rectangles represent the up-regulation of genes, while green rectangles represent down-regulation. 
A
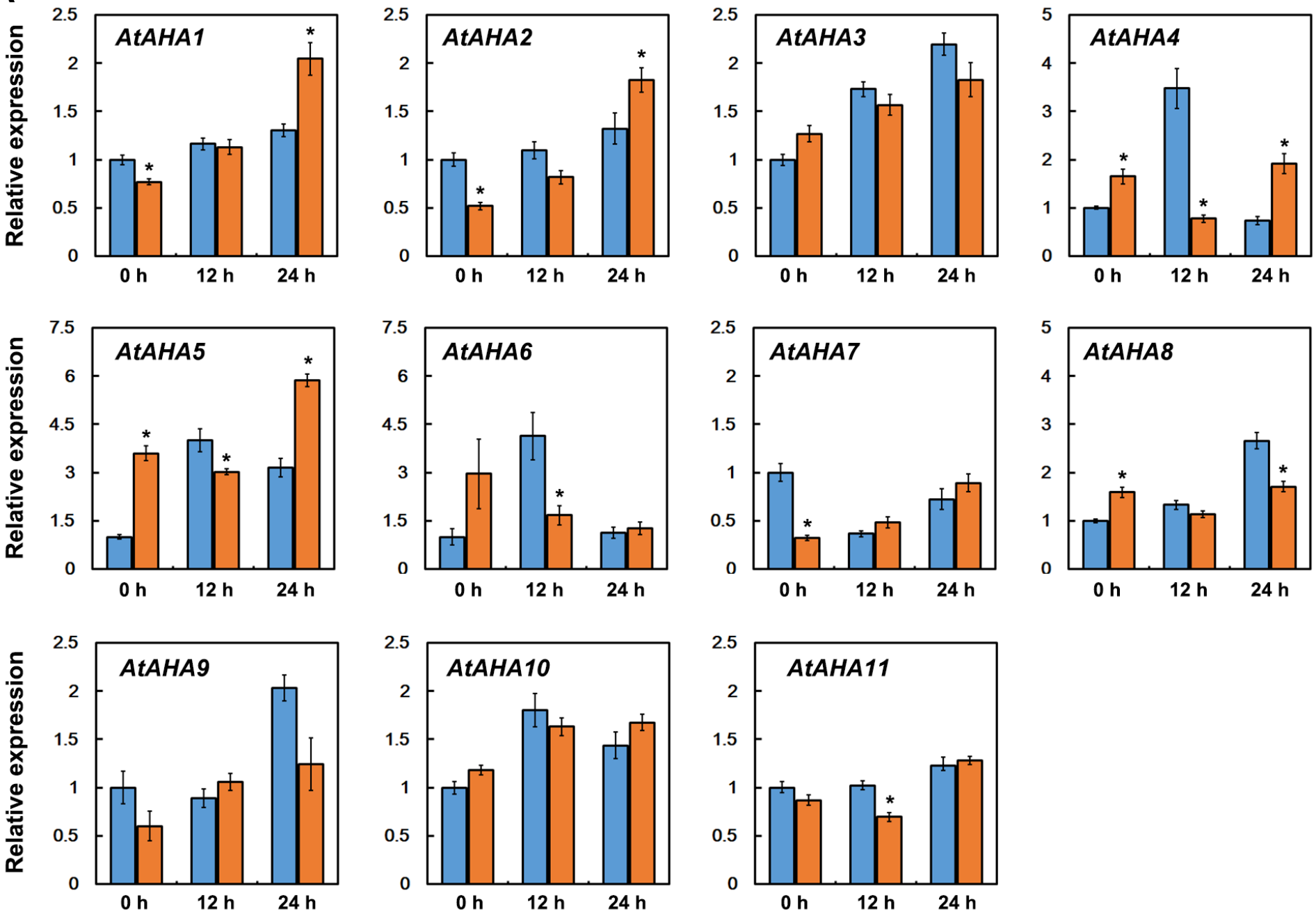

B
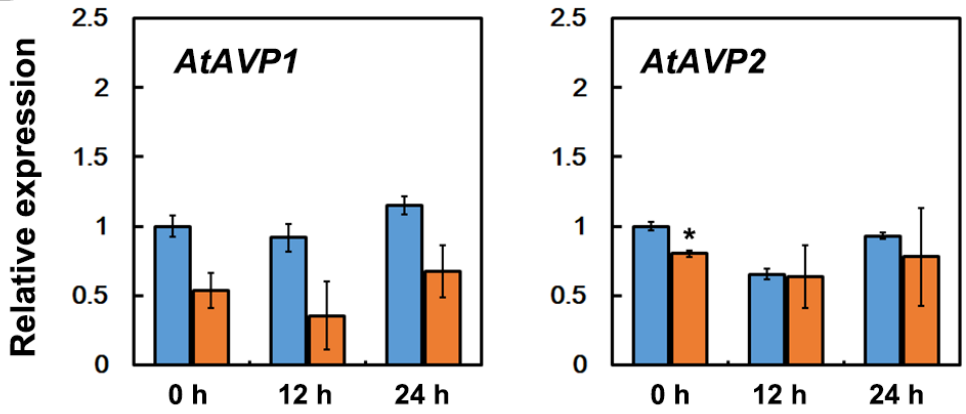

Col-0

atvha-d2

Figure 9

qPCR analysis of P-ATPase (AtAHA) and V-PPase (AtAVP) gene expression in Col-0 and the atvha-d2 mutant under normal and oxidative stress. The P-ATPase gene family contains 11 members (AtAHA1 to AtAHA11) (A) and the V-PPase contains two members (AtAVP1 and AtAVP2) (B). Asterisks indicate a significant difference between Col-0 and the atvha-d2 plants ( ${ }^{*}<0.01$; Student's $t$ test). Error bars indicate SE $(n=3)$.

\section{Supplementary Files}


This is a list of supplementary files associated with this preprint. Click to download.

- SupplementaryTableS3.xlsx

- FigureS1.docx

- SupplementaryTableS2.xlsx

- SupplementaryTableS1.xlsx 